\title{
Life at the top: the benefits of height
}

\author{
Angus Deaton and \\ Princeton University \\ Raksha Arora [Consultant] \\ Gallup
}

\section{Abstract}

According to the Gallup-Healthways Well-Being Index daily poll of the US population, taller people live better lives, at least on average. They evaluate their lives more favorably, and they are more likely to report a range of positive emotions such as enjoyment and happiness. They are also less likely to report a range of negative experiences, like sadness, and physical pain, though they are more likely to experience stress and anger, and if they are women, to worry. These findings cannot be attributed to different demographic or ethnic characteristics of taller people, but are almost entirely explained by the positive association between height and both income and education, both of which are positively linked to better lives.

\section{Keywords}

Height; emotions; wellbeing; income; education

\begin{abstract}
We use data from the Gallup-Healthways Well-Being Index daily polling to investigate the relationship between height and a range of emotional and evaluative outcomes. The Well-Being Index (WBI) polling was initiated in January 2008, and collects data by telephone survey (including cell phone only households) from around 1,000 respondents each day; further information is available at http://www.well-beingindex.com. We use information on 454,065 adults aged 18 or over interviewed from January $2^{\text {nd }} 2008$ to April $16^{\text {th }} 2009$. People were asked to report their heights, as well as an evaluation of their lives using the Cantril "selfanchoring striving scale", Cantril (1965). According to this, they are asked to imagine a ladder with steps numbered from zero at the bottom to ten at the top where the top of the ladder represents "the best possible life for you" and the bottom of the ladder represents "the worst possible life for you," and are asked to report on which step of the ladder they stand at the present time. The WBI poll also asks respondents to reply yes or no to questions about whether, in the day before the interview, they experienced a number of feelings "during a lot of the day." The question is asked about enjoyment, physical pain, happiness, worry, sadness, stress, and anger.
\end{abstract}

Men who are above average height (5 feet 10 inches) report that they are a little more than oneseventh of a step on the ladder above men who are below average height, average ladder score of 6.55 versus 6.41. For women, the difference is smaller, with women of below average height

Corresponding Author: Angus Deaton, 328 Wallace Hall, Princeton University, Princeton, NJ 08544, (1)-609-258-5967, deaton@ princeton.edu.

Publisher's Disclaimer: This is a PDF file of an unedited manuscript that has been accepted for publication. As a service to our customers we are providing this early version of the manuscript. The manuscript will undergo copyediting, typesetting, and review of the resulting proof before it is published in its final citable form. Please note that during the production process errors may be discovered which could affect the content, and all legal disclaimers that apply to the journal pertain. 
(5 feet 4 inches) a little less than one tenth of a step below women of above average height, average ladder score 6.55 versus 6.64 . These differences may seem small, but if we compare them to other factors that affect the ladder, they are actually quite substantial. One of the most consistently powerful predictors of life evaluation is income. The WBI poll has a single question about family income, grouped into eleven classes. The regression coefficient of the ladder on the logarithm of family income is 0.54 for women and 0.60 for men (for the 164,878 women and 178,440 men who provided income data), so that moving from below average to above average height has the same effect as an 18 percent increase in family income for women, and a 24 percent increase for men. We can also do this calculation by comparing the effect of an additional inch of height on the ladder ( 0.020 of a step for women, and 0.026 for men) with the effect of a change in income. According to this comparison, each additional inch of height has the same effect on reported life evaluation as a 3.8 percent increase in family income for women, and 4.4 percent increase for men.

Figure 1 shows the average heights of men and women on different steps of Cantril's selfanchoring striving scale. On average, men who report that their lives are the "worst possible" are more than eight tenths of an inch shorter than the average man; women on the bottom step are shorter than the average woman too, but by half an inch. As we move up the ladder of life, heights increase, at least until the seventh step. Surprisingly, people who say that their lives are the "best possible" are slightly shorter on average than those who are a step or two below; perhaps the eight percent of people who think their lives cannot be improved are different in some other respect.

Higher life evaluation is not the only outcome differentially associated with being tall. The WBI poll also asks respondents about enjoyment, physical pain, happiness, worry, sadness, stress, and anger. Table 1 shows, broken down by men and women and by above and below average height, the fraction of respondents who report experiencing each of these "during a lot of the day yesterday." The table also shows the percentage change in reported family income that would give the same change in the probability of reporting the experience as would an additional inch in height. Taller men and women are more likely to report enjoyment and happiness, and less likely to report pain and sadness, with the difference in sadness particularly large. Taller men, although not taller women, also worry less. Stress and anger, however, and are more likely to be experienced by people of above average height. The final columns in each half of the table show that, in most cases, the effect of height parallels the effect of income, with an additional inch of height improving outcomes by about the same as a 4.5 to 8.5 percentage increase in family income. Once again, worry (for women), stress and anger break the pattern, most egregiously in the case of stress where higher incomes are associated with less stress, so that this is the most marked case in which height does not play an income-like role. As we shall see below, this anomaly vanishes once we adjust for ethnicity.

Why do taller people do better on so many outcomes? Table 2 investigates alternative explanations by including successively more covariates in a series of regressions. The first column shows the effects of height in a regression that contains only height and a gender dummy; this baseline column provides results that are comparable to those in Table 1, albeit with men and women combined. Column 2 adds a set of age dummies, dummies for race and ethnicity (white, black, Asian, Hispanic, other) and for marital status (never married, married, separated, divorced, widowed, and domestic partnership.) For the ladder and most of the reported experiences, the inclusion of these socio-demographic controls does not affect the coefficient on height, so that we cannot attribute the effects of height to the different demographics of taller and shorter people. The exceptions, perhaps not surprisingly, are stress and anger, where the negative effects of heights are reversed once we include the racial and ethnicity dummies. This happens because whites report more stress and anger than do blacks, Asians, or Hispanics, and while blacks are about the same height as whites, Asians and 
Hispanics are shorter so that, without controls for ethnicity, their lower stress and anger levels are spuriously attributed to their lower heights.

We have run these regressions separately for whites (376,597 observations), Hispanics (10,191 observations), African-Americans $(29,612)$, and Asians $(5,968)$. Not surprisingly, the results for whites are almost identical to those in Table 2, as are those for Hispanics. For AfricanAmericans and Asians however, it is not the case that taller individuals have better ladder scores, although some of the results in the first column do carry through to those groups.

The inclusion of education and income in Column 3 of Table 2 has dramatic effects on the estimated coefficients of height. Conditional on education and income, height has no effect on stress or anger, and the effects on the other outcomes are very small-though sometimes still significant given that there are more than 400,000 observations. Taller people still have higher life evaluation, more enjoyment, more happiness, less worry, and less sadness, though the effects around a fourth or a fifth of the unconditional effects and seem too small to be of substantive interest. The conditional effect of height on pain is now positive, but an extra inch of height increases the probability of reporting pain only by six hundredths of one percent. Most of the (unconditional) benefits of height work through the fact that taller people are better educated and have higher incomes. As the last column of the table shows, income has strong beneficial effects on all of the outcomes, enhancing life evaluation, enjoyment, happiness, and diminishing pain, worry, sadness, stress, and anger. Education is usually beneficial too (results not reported here), but the effects are less uniform, particularly for worry, stress and anger. Conditional on income and the other socio-demographic covariates, education has essentially no effect on worry. The lowest level of anger and stress are reported by those who have less than a high school diploma, but for those with more education, anger and stress diminish with education, so that those with post-graduate qualifications have much the same levels of anger and stress as those who did not graduate from high school.

As a robustness check, we have recalculated the most inclusive regressions with the inclusion of dummy variables for each day of the survey; this will protect us against the presence of possible time effects. However, the estimates in Table 2 are not affected at all.

Figures 2 and 3 are similar to Figure 1, but now show the deviations in heights, not by steps of the ladder of life, but by income categories and by education groups. Since both income and education vary with age - older people tend to have higher incomes but less education — and because younger people are taller, we have adjusted these graphs for age. The basic data come from regressions of the deviation of height from its mean on a set of age and education or income dummies, run separately for education and income, and for males and females. The bars are then the predicted values for each education or income group, calculated for someone in their 30s. No interactions between age and education or income were included, so standardizing on another age would simply move all the bars by a fixed amount.

The two bottom income groups, where people report no income, or a monthly income of less than $\$ 60$, should not be treated seriously-true income of those respondents is likely much higher, and their permanent income is certainly so. (Think of self-employment business people whose current incomes may be technically zero or even negative, but who may be quite welloff.) The third group from the bottom may also contain a substantial fraction of people whose incomes are temporarily low. But above those groups, there is a steady increase in average height for higher income groups, especially for men. (Family income may sometimes be a more accurate indicator of men's than of women's earnings.) Figure 3 shows the comparable effects for education. Misreporting is a less serious issue for education than for income, and education, unlike income, is not affected by transitory fluctuations, and here the relationship is monotonic. Controlling for age, men who did not graduate from high school are half an inch shorter than 
average, and are more than an inch shorter than the average college-educated man. The differences are only a little less for women.

Why is it that taller people should be better educated and have higher incomes. One persuasive if provocative answer has recently been given by Anne Case and Christina Paxson (2008); taller people are more likely than shorter people to have reached their full cognitive potential.

Their story goes back to the first years of childhood. If everything goes according to plan, if children are well-nourished throughout their childhood, and they are kept away from childhood diseases that might slow their growth, they will eventually reach the adult height set by their genetic potential. Children from taller families will be taller, and children from shorter families will be shorter, but there will be no effect of height on adult outcomes. But not everything always goes according to plan, and perhaps through lack of good nutrition, or through exposure to disease, some children will not attain their full potential height. Moreover there is good evidence that cognitive and physical function develop together, so that children who do not reach their potential heights also do not develop their full cognitive potential. It is this lack of full cognitive development that accounts for lower levels of education, and lower earnings in adulthood which, in turn, are almost entirely responsible for lower levels of life evaluation, and poorer emotional outcomes. That height should be associated with these outcomes is predicted by Case and Paxson's analysis, and the results from the Gallup-Healthways WellBeing Index daily poll provide support for their interpretation.

\section{Acknowledgments}

We are grateful to Gallup and Healthways for access to the proprietary data from their Gallup-Healthways Well-Being Index daily poll. Deaton acknowledges financial support from the National Institute on Aging through grant $P 01$ AG05842-14 to the National Bureau of Economic Research and grant P30 AG024361 to Princeton. A summary of this work, intended for a general audience, appeared on gallup.com. We are grateful to Jim Harter, John Komlos, and Eric Nielsen for comments.

\section{References}

Cantril, Hadley. The pattern of human concern. New Brunswick, NJ: Rutgers University Press; 1965.

Case, Anne; Paxson, Christina. Stature and status: height, ability, and labor market outcomes. Journal of Political Economy 2008;116(3):499-532. [PubMed: 19603086] 


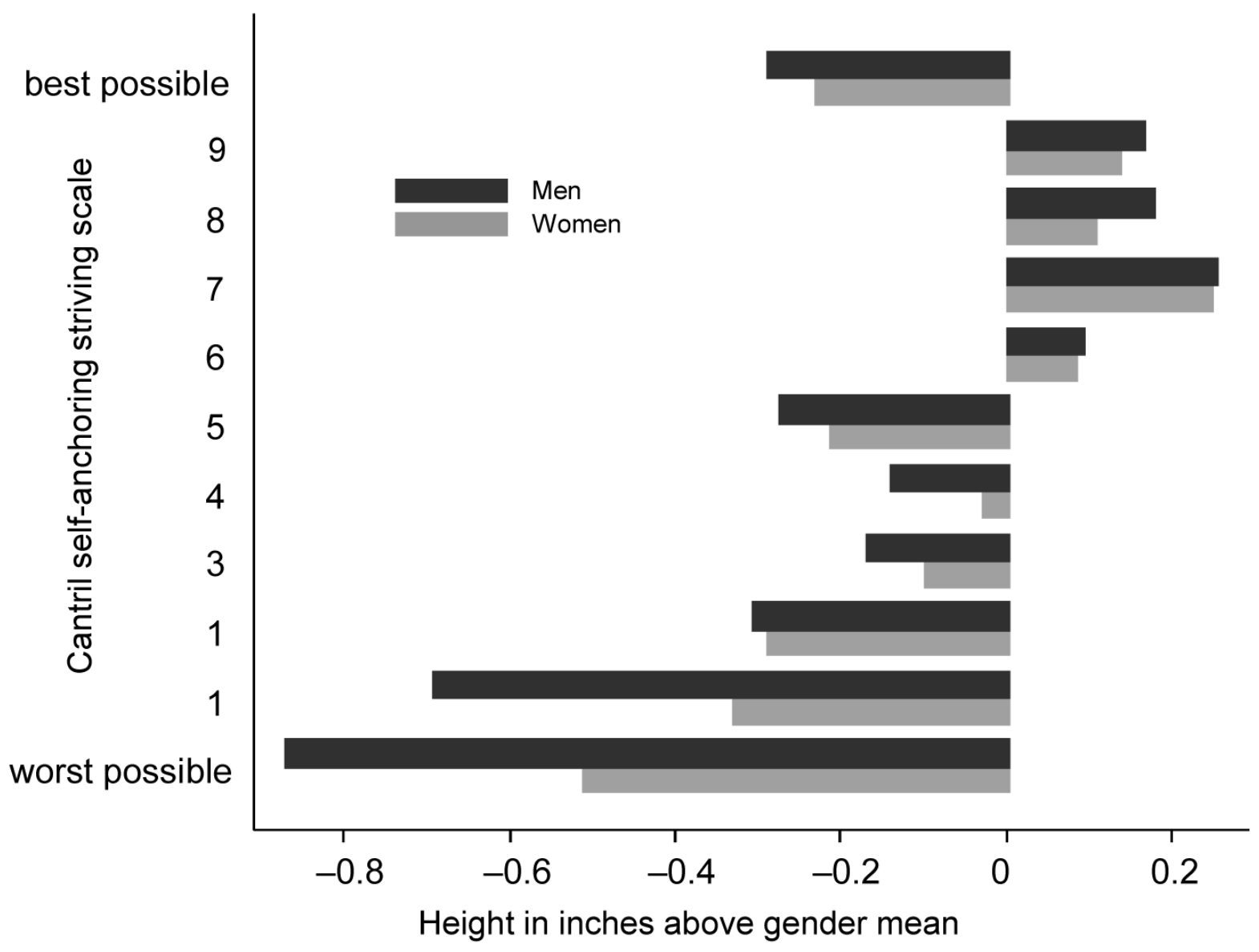

Figure 1.

Height and the evolution of life. 


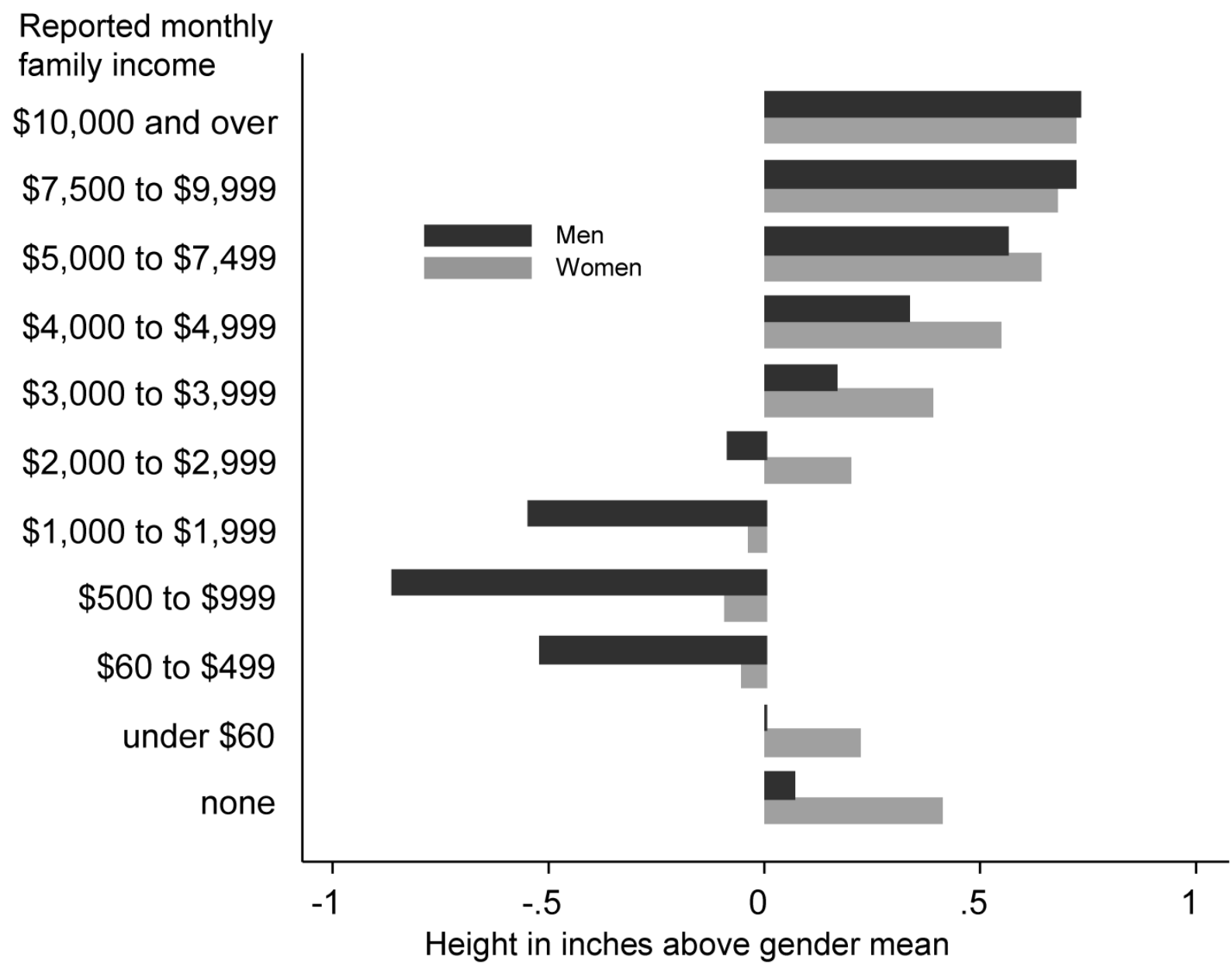

Figure 2.

Height by reported family income. 


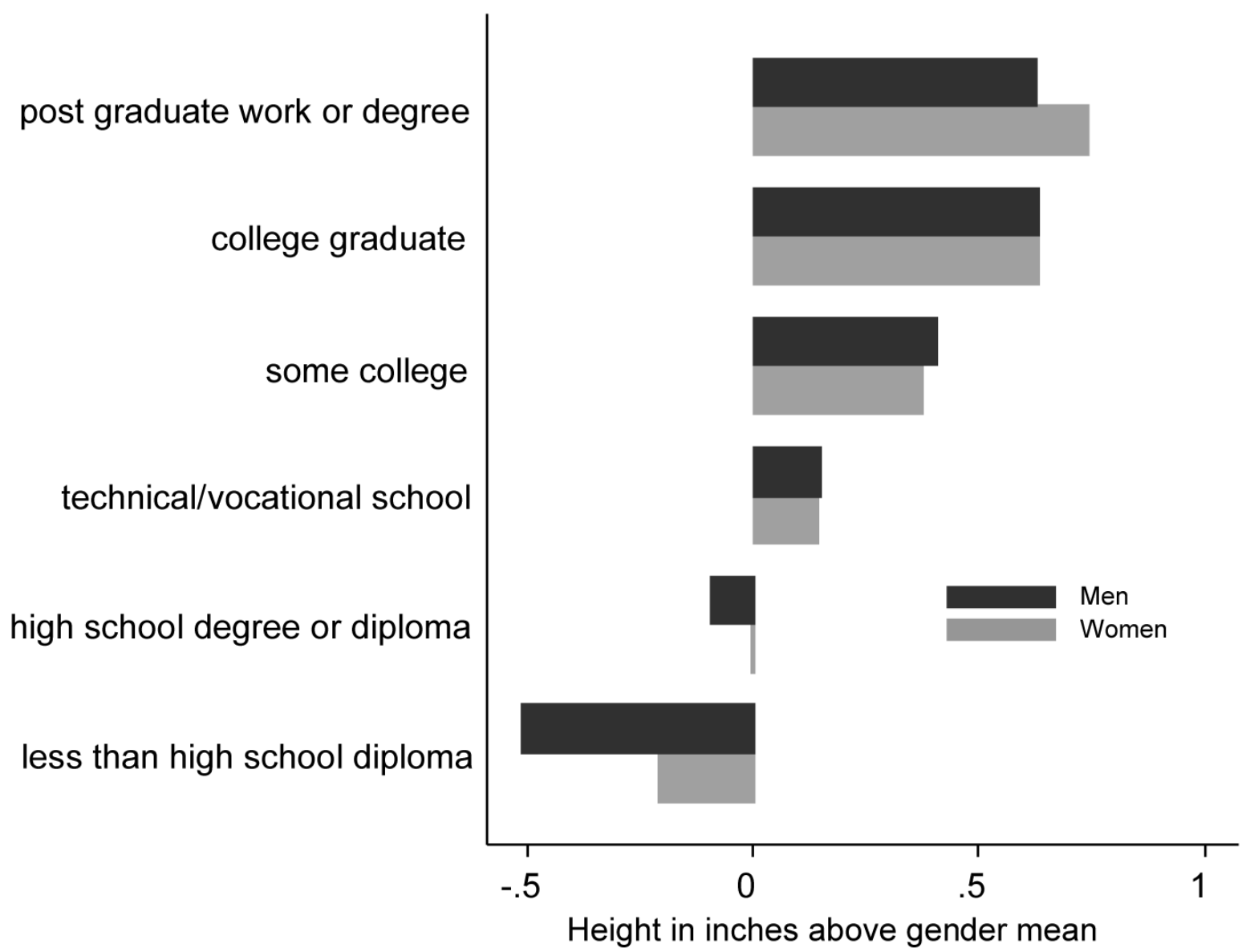

Figure 3.

Height by education. 


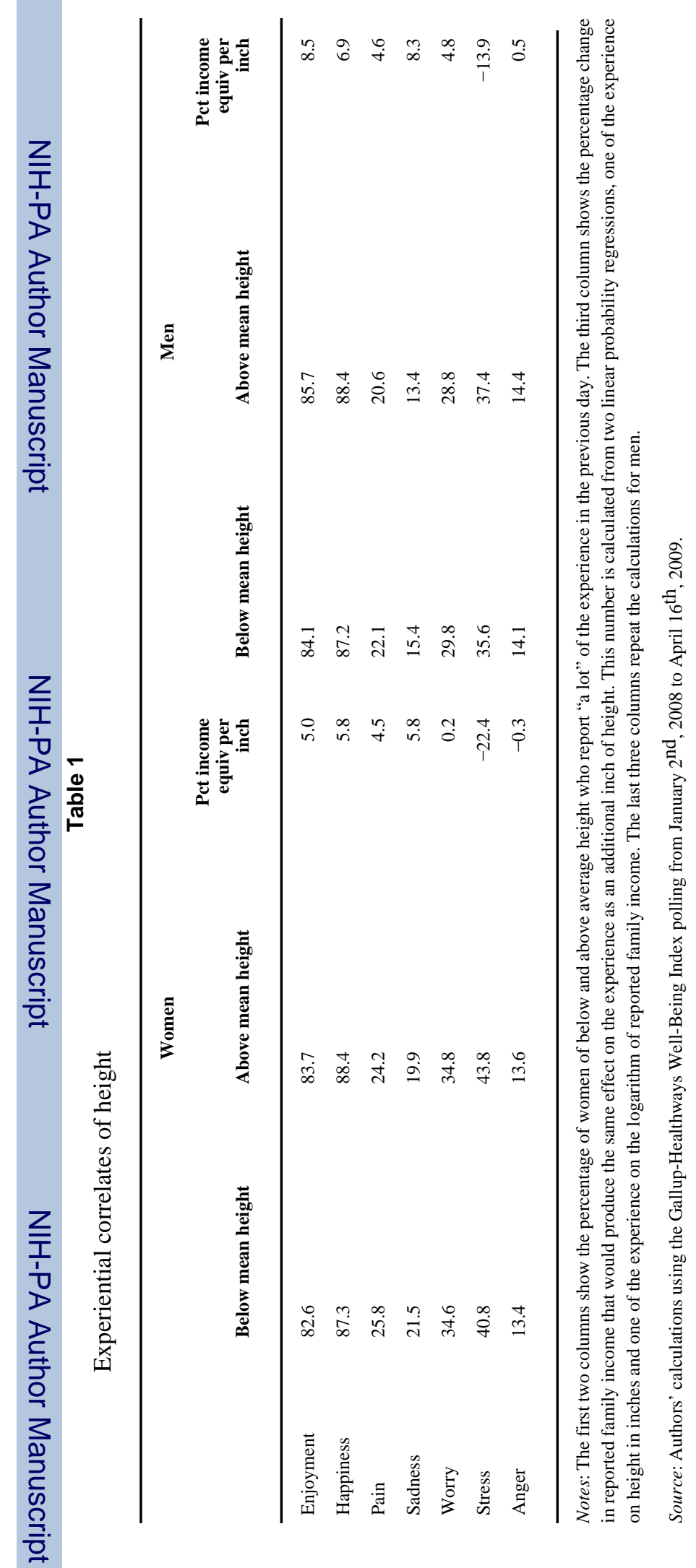

Econ Hum Biol. Author manuscript; available in PMC 2010 July 1. 
Table 2

Regressions of wellbeing and health outcomes on height with different controls

\begin{tabular}{lcccc}
\hline & Sex and height & Adding socio-demographics & $\begin{array}{c}\text { Adding education } \\
\text { and income } \\
\text { categories }\end{array}$ & $\begin{array}{c}\text { Coefficient on log } \\
\text { family income }\end{array}$ \\
& $\mathbf{( 1 )}$ & $\mathbf{( 2 )}$ & $\mathbf{( 3 )}$ & $\mathbf{( 4 )}$ \\
\hline Ladder & $0.0215(20.1)$ & $0.0252(23.1)$ & $0.0058(4.9)$ & $0.5347(105.6)$ \\
Enjoyment & $0.0025(13.4)$ & $0.0026(14.1)$ & $0.0010(4.6)$ & $0.0386(45.0)$ \\
Happiness & $0.0022(13.0)$ & $0.0017(9.7)$ & $0.0004(2.1)$ & $0.0319(40.7)$ \\
Pain & $-0.0035(16.7)$ & $-0.0021(9.6)$ & $0.0006(2.5)$ & $-0.0703(66.5)$ \\
Sadness & $-0.0039(20.0)$ & $-0.0031(16.1)$ & $-0.0014(6.3)$ & $-0.0387(29.0)$ \\
Worry & $-0.0005(2.0)$ & $-0.0030(12.9)$ & $-0.0010(3.7)$ & $-0.0615(55.7)$ \\
Stress & $0.0046(18.3)$ & $-0.0012(5.0)$ & $-0.0002(0.8)$ & $-0.0387(29.0)$ \\
Anger & $0.0005(2.9)$ & $-0.0009(5.0)$ & $0.0000(0.1)$ & $-0.0216(26.4)$ \\
\hline
\end{tabular}

Notes: The first three columns show the coefficient of height in an OLS regression with the experience as the dependent variable; the ladder takes values from 0 to 10, and the others are dichotomous. In the first column, the only variables are height in inches and a sex dummy. The second column adds dummies for race and ethnicity, for age, and for marital status, while the third column has the same variables as the second column plus dummies for age and income categories. The coefficient in the final column comes from a regression with the same variables as in the third column, but with the income categories replaced by the logarithm of income. Figures in brackets are absolute $t$-values, clustered by interview date.

Source: Authors' calculations using Gallup-Healthways Well-Being Index polls from January $2^{\text {nd }}, 2008$ to April $16^{\text {th }}, 2009$. Ladder ranking is based on the Cantril self-anchoring striving scale. 